\title{
Sociodemographic Profiles And Psychiatric Comorbidities Among Patients With Alcohol Dependence In Western Nepal
}

\author{
Belbase $\mathbf{M}^{1}$, Jalan RK${ }^{2}$, Adhikari $\mathbf{J}^{3}$ \\ 1. Associate Professor, Dept Of Psychiatry, Nepalgunj Medical College, Kohalpur, Banke, Nepal \\ 2. Assistant Professor, Dept Of Psychiatry, Nepalgunj Medical College, Kohalpur, Banke, Nepal \\ 3. Assistant Professor, Dept Of Paediatrics, Nepalgunj Medical College, Kohalpur, Banke, Nepal
}

E-mail *Corresponding author : mohanbelbase90@ gmail.com

\begin{abstract}
Introduction: Alcohol is a potent drug that causes acute and chronic changes in almost all neurochemical systems and heavy drinking can produce serious temporary psychological symptoms including depression, anxiety and psychoses. Alcoholism is clinically heterogenous disorder with variable age of onset, drinking patterns, severity and comorbidity with other mental disorders. There is a gender difference in many aspect of alcohol use. The aim of the study was to study the sociodemographic profile, severity, gender difference and psychiatric comorbidities in patient with alcohol dependence syndrome in Nepalese population.
\end{abstract}

Material And Method: This is a hospital based study done in patients coming to Nepalgunj Medical College, Kohalpur over a period of one year from June 2019 to May 2020 on consecutive serial basis. Diagnosis of alcohol dependence was made based on International Classification of Disease-10 (ICD-10) criteria. Semi structured proforma and Severity of Alcohol Dependence Questionnaire (SADQ) was applied in those patients and recorded accordingly. The data was analyzed using SPSS.

Results: Out of 40 patients studied (N-40), $37(92.5 \%)$ were male and $3(7.5 \%)$ were female. Alcohol dependence is most common in the age bracket of 30-39 (43.1\%) followed by 40-49 (33.4\%) with mean age of 40.3 years and the mean age of duration of alcohol use being 13.45 years. The mean amount of alcohol consumed per day is 92.25 grams. The SADQ scores, age of first alcohol use, duration of alcohol use in years and daily amount of alcohol use in grams is significantly different between male and female. Similarly there is severe alcohol dependence in $75 \%$ while moderate level in $25 \%$ of study population. Regarding psychiatric comorbidities, $90 \%$ have comorbid other substance use disorder followed by anxiety disorders in $37.5 \%$, personality disorders in $35 \%$, mood disorders in $32.5 \%$, deliberate self harm in $30 \%$ and psychotic disorders in $12.5 \%$.

Conclusion: Alcohol dependence is most commonly found in young and adults of various age group. Age of first alcohol use, duration of alcohol use in years and daily amount of alcohol use in grams is significantly different between male and female. Alcohol dependence is comorbid with multiple psychiatric entities.

Keywords: Alcohol, comorbidities, International Classification of Disease-10 (ICD-10), Severity of Alcohol Dependence Questionnaire (SADQ)

\section{INTRODUCTION}

Alcohol is most commonly abused psychoactive substance worldwide. Evidence of human consumption dates back at least 12000 years when it was used for pleasure, nutrition and medicinal value. ${ }^{1}$

Commonly considered as a social lubricants, from heath point of view it is considered to be a kind of "drug", that is if taken by living organism, may modify one or more of its functions. Alcohol dependence is described as a state, psychic and sometimes also physical resulting from interaction between a living organism and a drug (alcohol), characterized by behavioral and other responses that always include a compulsion to take the drug (alcohol) on a continuous or periodic basis in order to experience its psychic effects, and sometimes to avoid the discomfort of it absence. ${ }^{2}$ 
Alcohol is a potent drug that causes acute and chronic changes in almost all neurochemical systems, with the result that heavy drinking can produce serious temporary psychological symptoms including depression, anxiety and psychoses. Several preexisting psychiatric entities including antisocial personality, bipolar and schizophrenia increases the risk of later alcohol use disorders. ${ }^{1}$

There are several causes of alcohol dependence that can be considered biological, psychological and social commonly said to be biopsychosocial model of alcoholism. ${ }^{1,3,4}$ Role of genetics is very high with 3-4 fold increased risk of severe alcohol problems in close relatives in individuals with alcohol use disorder (AUD). Other psychological and sociocultural factors related to heavy drinking is neighborhood, availability of alcohol, persons income, education and religion. ${ }^{1,3}$ Thus the alcohol use disorder is a complex, multifaceted cluster of behavioral, cognitive and psychological symptoms. ${ }^{5}$

In United States, as per 2010 World Health Organization report, the life time risk of AUD is about $15 \%$ for men and $10 \%$ for women with 1 year prevalence rate of about $6 \%$. The peak age of onset of AUD is from early 20 to about age $40.1^{1}$ In United States, one in seven person who starts drinking will also develop alcohol dependence disorder in the course of their lives. ${ }^{3}$ Alcohol can cause physical, psychological and social problems. Heavy drinking can cause confusion in diagnosing mental problems as it may cause drinking related sign and symptoms, drinking induced psychiatric problems and exacerbation of independent psychiatric entities. About 10-20 \% people who drinks excessive alcohol , develops cirrhosis of liver. ${ }^{4}$ Other side effects of chronic alcohol use are insomnia, cerebellar degenerations, Wernicke's encephalopathy, fetal alcohol syndrome, severe anterograde amnesia (Korsakoff's), peripheral neuropathy, gastrointestinal problems, cardiovascular problems, problems in blood producing systems, cancer and alcohol also cuts off decades or more the lifespan. ${ }^{1}$ It is clinically a heterogeneous disorder with variable age of onset, drinking patterns, severity and comorbidity with other mental disorders. ${ }^{2}$

The aim of this article to study the various sociodemographic factors associated in alcohol dependence and type of complications and mental comorbidities in Nepalese population.

\section{MATERIAL AND METHOD}

This is a hospital based study done in patients coming to Nepalgunj Medical College, Kohalpur over a period of one year from June 2019 to May 2020 on consecutive serial basis. All patients coming to out patient department, referred from emergency and other departments and inpatients were included. Only patients having alcohol use disorder fulfilling International Classification of Disease (ICD-10) criteria of alcohol dependence were selected and enrolled after their written consent. Others patients having multiple substance use in dependent pattern, refusing the consent, having intellectual disability, patients with head injury or fever were not included in the study. When selecting patient from multiple substance use, the only patients who were dependent on alcohol at present were selected. Cross sectional psychiatric comorbidity was recorded. Total 40 patients were enrolled with 3 female and 37 male with the age from 18 to 62 years. Needful investigations including complete blood count, liver function tests, ultrasonogram of abdomen were done.

Sociodemographic information was recorded in the proforma developed by the department of psychiatry. It included various information including patient's age, gender, marital status, religion, education, occupation and socioeconomic status. Severity of Alcohol Dependence Questionnaire (SADQ) was applied in front of family members to reconfirm the issues on the date of discharge to inpatients or after a week of first hospital visit to out patients to avoid confusion caused by delirium tremens. SADQ is a 20 point checklist rated on 4 points that was developed by addiction research unit at Maudsley hospital. It measures the severity of alcohol dependence. Score of less than 16 is mild dependence, $16-30$ is moderate while more than 31 indicates severe alcohol dependence. Information about drinking age, pattern, amount and frequencies was collected. Calculation of local beverage (undistilled and distilled) and its alcohol content in gram was made based on information given by a Nation Wide Survey entitled Nepalese Homebrewed Alcoholic Beverages: Types, Ingredients and 
Ethanol concentration. ${ }^{6}$ As ethanol concentration in homebrewed alcohol distilled was $14 \%(3-40)$ and nondistilled 5.2\% (1-18.9), distilled was considered as equivalent to wine and nondistilled was considered as equivalent to beer for the ease of calculation of alcohol content in grams. The amount of alcohol consumed was calculated in grams as $30 \mathrm{ml}$ of spirits, $50 \mathrm{ml}$ of arrack/ vodka/rum, $100 \mathrm{ml}$ of wine and $250 \mathrm{ml}$ of beer equivalent to $10 \mathrm{gm}$.

Data were collected and assessed using SPSS $11.5 \mathrm{~V}$. For descriptive statistics mean, standard deviation, maximum values and percentage were calculated. For inferential statistics $t$ test was applied to find out the significant difference between gender and other variables, and Pearson's correlation coefficient was applied to find out the significant correlation between SADQ and other numerical variables. The level of significant was considered $\mathrm{p}<0.05$.

Instruments used in this study are,

1. The ICD 10 classification of mental and behavioral disorders, clinical description and diagnostic guidelines for Alcohol use disorder. $^{7}$

2. Semi-stuctured porforma for demographic profile developed by department of psychiatry

3. Severity of Alcohol Dependence Questionnaire (SADQ)

\section{RESULT}

Out of total 40 participants, 37 were male and only 3 were female. Most patients were of age 30-39 and 40-49 age brackets that included $70 \%$ of the total. About $90 \%$ were married and literate population covered $75 \%$ of study populations. Most of them (80\%) were from lower middle socioeconomic background.

The mean age of the study population was 40.3 years with standard deviation of 10.29 with the age range of 18-62 years. The mean SADQ score was 34.33 with standard deviation of 4.59 . Similarly mean age of first alcohol drink was 19.43 years with standard deviation of 3.72 years. The mean age of duration of alcohol use was 13.45 years with standard deviation of 7.74 years. The mean amount of alcohol consumed per day was 92.25 grams with standard deviation of 23.94 grams.
Table 1: Sociodemographic profile of the patients with alcohol dependence syndrome

\begin{tabular}{|l|l|l|l|}
\hline characteristics & categories & $\begin{array}{l}\text { frequency } \\
(\mathrm{N}=40)\end{array}$ & Percentage \\
\hline \multirow{5}{*}{ Age } & $<20$ & 1 & 2.5 \\
& $20-29$ & 5 & 12.5 \\
& $30-39$ & 14 & 35 \\
& $40-49$ & 14 & 35 \\
& $>50$ & 6 & 15 \\
\hline Gender & Male & 37 & 92.5 \\
& Female & 3 & 7.5 \\
\hline Marital status & Married & 36 & 90 \\
& Unmarried & 4 & 10 \\
\hline \multirow{4}{*}{ Religion } & Hindu & 38 & 95 \\
\hline Education & Christian & 2 & 5 \\
& Illiterate & 6 & 15 \\
& Literate & 30 & 75 \\
& Higher & 4 & 10 \\
& education & & \\
\hline \multirow{5}{*}{ Occupation } & Student & 2 & 5 \\
& Housewife & 3 & 7.5 \\
& Jobholder & 8 & 20 \\
\hline \multirow{3}{*}{$\begin{array}{l}\text { Socioeconomic } \\
\text { status }\end{array}$} & Unemployed & 27 & 67.5 \\
\hline & Lower & 8 & 20 \\
& Lower- & 32 & 80 \\
middle & & \\
\hline
\end{tabular}

While comparing between gender regarding SADQ scores using $t$ test, age of first alcohol use, duration of alcohol use in years and daily amount of alcohol use in grams was significantly different between male and female except for their age which was not significant.

While correlating between SADQ scores and amount of alcohol use in grams per day, it was highly significant with $\mathrm{p}$ value of $<0.001$ Similarly SADQ score and duration of alcohol use in years was also significantly correlated with $p$ value of 0.040 .

Regarding the degree of alcohol dependence based on SADQ score, most of the cases were of severe ADS $(75 \%)$ while $25 \%$ were of moderate level of dependence.

Regarding psychiatric comorbidities in the patient with ADS, $90 \%$ had comorbid other substance use disorder particularly nicotine. 
Anxiety spectrum disorder was found in $37.5 \%$ followed by personality disorders/trait in $35 \%$ of participants while mood disorder was found in $32.5 \%$. Suicidal behaviors with deliberate self harm was found in $30 \%$ of participants.

Table 2: The mean and standard deviations of different variables

\begin{tabular}{|l|c|c|c|c|}
\hline \multirow{2}{*}{ Variable } & \multicolumn{4}{|c|}{ Statistics } \\
\cline { 2 - 5 } & Mean & SD & Minimum & Maximum \\
\hline Age & 40.03 & 10.29 & 18 & 62 \\
\hline SADQ scores & 34.33 & 4.59 & 26 & 44 \\
\hline $\begin{array}{l}\text { Age of 1st } \\
\text { drink }\end{array}$ & 19.43 & 3.72 & 14 & 30 \\
\hline $\begin{array}{l}\text { Duration of } \\
\text { alcohol use } \\
\text { in years }\end{array}$ & 13.45 & 7.74 & 1 & 32 \\
\hline $\begin{array}{l}\text { Amount of } \\
\text { alcohol in } \\
\text { grams }\end{array}$ & 92.25 & 23.94 & 55 & 140 \\
\hline
\end{tabular}

Table 3: Comparison of male and female with respect to age of first drink, duration of alcohol use, amount of alcohol and age in years

\begin{tabular}{|l|c|c|c|c|c|c|}
\hline \multirow{2}{*}{\multicolumn{1}{|c|}{ Variable }} & \multicolumn{2}{c|}{ Female } & \multicolumn{2}{c|}{ Male } & \multirow{2}{*}{ P value } & \multirow{2}{*}{ Remarks } \\
\cline { 2 - 7 } & Mean & SD & Mean & SD & & \\
\hline SADQ scores & 27.00 & 1.73 & 34.92 & 4.23 & 0.003 & Sig \\
\hline Age of 1st drink & 25.67 & 0.58 & 18.92 & 3.39 & 0.002 & Sig \\
\hline Duration of alcohol use in years & 3.67 & 1.53 & 14.24 & 7.50 & 0.021 & Sig \\
\hline Amount of alcohol in gms & 70.00 & 10.00 & 94.05 & 23.89 & 0.024 & Sig \\
\hline Age in years & 35.33 & 4.16 & 40.41 & 10.57 & 0.419 & NS \\
\hline
\end{tabular}

Table 4: Correlation between SADQ score and patients age, age at first alcohol drink, duration of alcohol use and amount of alcohol

\begin{tabular}{|l|c|c|}
\hline \multicolumn{3}{|c|}{ Correlations } \\
\hline \multirow{2}{*}{ Variable } & \multicolumn{2}{|c|}{ SADQ scores } \\
\cline { 2 - 3 } & Correlation & P Value \\
\hline Age in years & 0.307 & 0.054 \\
\hline Age of 1st drink & -0.089 & 0.584 \\
\hline $\begin{array}{l}\text { Duration of alcohol } \\
\text { use in years }\end{array}$ & $0.327^{*}$ & 0.040 \\
\hline $\begin{array}{l}\text { Amount of alcohol } \\
\text { in gms }\end{array}$ & $0.759^{* *}$ & $<0.001$ \\
\hline
\end{tabular}

* Significant and ${ }^{* *}$ Highly Significant
Table 5: Psychiatric comorbidities in patients with alcohol dependence

\begin{tabular}{|l|l|l|}
\hline $\begin{array}{l}\text { Other psychiatric } \\
\text { comorbidities (Induced/ } \\
\text { independent) (N=40) }\end{array}$ & Frequency & Percentage \\
\hline $\begin{array}{l}\text { Cognitiv dysfunctions } \\
\text { (dementia, delirium, } \\
\text { amnestic syndromes) }\end{array}$ & 5 & 12.5 \\
\hline $\begin{array}{l}\text { Other comorbid substances } \\
\text { (tobacco, cannabis, } \\
\text { Caffeine, opoids) }\end{array}$ & 36 & 90 \\
\hline $\begin{array}{l}\text { Psychotic disorders } \\
\text { (persistent delusional } \\
\text { disorders, paranoid } \\
\text { delusions, hallucinations) }\end{array}$ & 5 & 12.5 \\
\hline $\begin{array}{l}\text { Mood disorders } \\
\text { (depression, mania, bipolar } \\
\text { affective disorders) }\end{array}$ & 13 & 32.5 \\
\hline $\begin{array}{l}\text { Anxiety disorders (GAD, } \\
\text { panic disorder, phobia) }\end{array}$ & 15 & 37.5 \\
\hline $\begin{array}{l}\text { Personality disorders } \\
\text { (boarderline, antisocial, } \\
\text { cluster A) }\end{array}$ & 14 & 35 \\
\hline $\begin{array}{l}\text { Deliberate self harm, } \\
\text { suicidal attempts }\end{array}$ & 12 & 30 \\
\hline
\end{tabular}




\section{DISCUSSION:}

Out of 40 participants $(\mathrm{N}=40), 37$ were male $(92.5 \%)$ while only 3 were female $(7.5 \%)$. Most patients were of 30-39 and 40-49 age brackets that included $70 \%$ of the total. About $90 \%$ were married and $95 \%$ were Hindu. Literate population has covered $75 \%$ of study populations and most of them $(80 \%)$ were from lower middle socioeconomic background. This is similar to one study regarding alcohol dependence from eastern Nepal where $82 \%$ were male while $18 \%$ were females. Most of the ADS patients were in the age bracket of 30-39 (43.1\%) followed by $40-49$ covering $33.4 \%$ of study population. The same study from eastern Nepal also shows $88.22 \%$ of study population are married and $85 \%$ literate which is similar to our findings. 8 Another study done in India regarding drinking patterns in persons with alcohol dependence shows similar findings with most of the patients being married $(77.5 \%)$, Hindu $(97.5 \%)$, literate $(75 \%)$ and from lower and middle socioeconomic status that coverers $87.5 \%$ of study populations. ${ }^{9}$

As per the results of our study, mean age of the study population is 40.3 years with standard deviation of 10.29 with the age range of 18-62 years. This is similar to one Indian study regarding drinking patterns in persons with alcohol dependence in which mean age of total sample is 42.08 years. Similarly mean age of first alcohol drink in our study is 19.43 years with standard deviation of 3.72 years. This is also similar to the findings of the same study where the mean age of first alcohol drink for total sample is 20.6 years. $^{9}$

The mean age of duration of alcohol use was 13.45 years with standard deviation of 7.74 years. The mean amount of alcohol consumed per day was 92.25 grams with standard deviation of 23.94 grams. This is similar to one another study done in western Nepal entitled Alcohol consumption pattern in Western Nepal: findings from the COBIN baseline survey where drinking respondents consumed 7.7 (standard deviation of 0.3 ) standard alcohol drinks on one occasion. ${ }^{10}$

While comparing between gender regarding SADQ scores, age of first alcohol use, duration of alcohol use in years and daily amount of alcohol use in grams, it was significantly different between male and female except for their age which was not significant.

While correlating between SADQ scores and amount of alcohol use in grams per day, it was highly significant with $\mathrm{p}$ value of $<0.001$ meaning increase in alcohol use in gram increases SADQ scores. Similarly SADQ score and duration of alcohol use in years was also significantly coorelated with $\mathrm{p}$ value of $<0.040$ meaning high SADQ scores is associated with increase in duration of alcohol use.

Regarding the degree of alcohol dependence based on SADQ score, most of the cases were of severe ADS (75 \%) while $25 \%$ were of moderate level of ADS. This is similar to one comparative study called severe alcohol-induced liver disease and alcohol dependence syndrome, where $76 \%$ patients in detox group was labeled as severe and $24 \%$ as moderate as per the SADQ scores. ${ }^{11}$ Regarding psychiatric comorbidities in the patient with ADS, $90 \%$ had comorbid other substance use disorder particularly nicotine. Anxiety spectrum disorder was found in $37.5 \%$ followed by personality disorders/trait in $35 \%$ of participants while mood disorder was found in $32.5 \%$ patients. Suicidal behaviors with deliberate self harm was found in $30 \%$ of participants. Similarly psychotic disorders was found in $12.5 \%$ of study populations. These finding of comorbidity are similar to the findings mentioned in most of the standard textbooks. 1,3,5 Similar findings form one study called prevalence and correlates of alcohol use in central Nepal district in which higher AUDIT scores were associated with depression, suicidality, dysfunctionality and internalized stigma. ${ }^{12}$

In another study assessing the psychiatric comorbidities in patients with alcohol dependence, out of 31 patients, $45 \%$ had psychiatric comorbidities with anxiety disorders having the frequency of $35.71 \%$ similar to our study findings. Depressive disorder accounts for $28.57 \%$ of comorbidity which is a bit lower than our findings but we have included mood disorders overall ( $32.5 \%)$ so that if we consider depression alone, its frequency should be similar. ${ }^{13}$

Another study done in Kathmandu enrolling 37 participants with the regular use of alcohol, alcohol induced psychotic disorder was found 
in $6.19 \%$ of study opulations. ${ }^{14}$ Our finding of $12.5 \%$ psychotic disorders in alcohol dependent patients must be due to inclusion of independent psychotic patients also who were regularly using alcohol in the background of ongoing psychotic phenomena.

Similarly suicidal attempts was found in $30 \%$ of participants in our study which is comparable in another similar descriptive hospital based study conducted in eastern Nepal regarding role of alcohol in suicide involving 150 suicidal attempts where a clear and possible association of alcohol was seen with suicidal attempts in 37 $\%$ of participants. ${ }^{15}$

Alcohol abuse can cause sign and symptoms of depression, anxiety, psychosis, and antisocial behavior, both during intoxication and during withdrawal. At times, these symptoms and signs cluster, last for few weeks, and mimics frank psychiatric disorders (alcohol induced syndromes). These alcohol related conditions usually disappear after several days or weeks of abstinence. Prematurely labeling these conditions as major depression, panic disorder, schizophrenia or ASPD can lead to misdiagnosis and inattention to a patient's alcohol related problem. ${ }^{16}$

Small sample size, unable to follow up, non blind type of study done is hospital based settings are some of limitations of this study.

\section{CONCLUSION:}

This study shows that ADS is widely prevalent in young and adults of various age group. The SADQ scores suggest significant difference between male and female with regard to age of first alcohol use, duration of alcohol use in years and daily amount of alcohol use in grams. Alcohol dependence is highly comorbid with other psychoactive substances, anxiety spectrum, personality issues, mood disorders, suicide, psychotic disorders and cognitive disorders.

ACKNOWLEDGEMENT: My sincere thanks LBEA (Lord Buddha Educational Academy), NGMCTH kohalpur and principal sir Prof. Dr. Moda Nath Marhatta for giving me this study opportunity. Thanks to my department colleagues and my students Dr. Rakesh Kumar Mehata and Dr. Saroj Upreti.

\section{FUNDING: None}

\section{CONFLICT OF INTEREST: None}

\section{REFERENCES:}

1. Schuckit MA. Alcohol-Related Disorders. In: Sadock BJ, Sadock VA, Ruiz P. Comprehensive textbook of psychiatry. 10 $10^{\text {th }}$ ed. Philadelphia: Wolters Kluwer; 2017. p. 1264-79.

2. Park K. Parks's Textbook of preventive and Social Medicine. 20th ed. Jabalpur: M/s Banarasidas Bhanot; 2009. p. 737.

3. Juan C, Gill N, Gill KJ, Marshal J, Mann KF, Kiefer F, et al. Alcohol use disorders. In: Gelder MG, Andreasen NC, Lopez-lbor JJ, et al. New oxford textbook of psychiatry. 2nd ed. New York: Oxford University Press; 2009. p. 432-71.

4. Desai NG, Gupta DK, Khurshid KA. Substance Use Disorders. In: Vyas JN, Auja N. Textbook of postgraduate psychiatry. $2^{\text {nd }}$ ed. New Delhi: Jaypee Brothers Medical Publisers; 1999. p. 77-88.

5. Babor TF, Hernandez-Avila CA, Ungemack JA. Substance-Related Disorders: Alcohol-related Disorders. In: Tasman A, Kay J, Lieberman JA, et al. Psychiatry. $4^{\text {th }}$ ed. The Atrium: Wiley Blackwell; 2015. p. 1401.

6. Thapa N, Aryal K, Paudel M, etal. Nepalese Homebrewed Alcoholic Bebverages: Types, Ingredients, and Ethanol Concentrations from a nation Wide Survey. Journal of Nepal Health Research Council. 2015 April; 13(29): 59-65

7. World Health Organization. The ICD-10 Classification of Mental and Behavioral Disorders: Clinical description and diagnostic guidelines. Geneva: World Health Orgaanization; 1992.

8. Shakya DR, Shyangwa PM, Sen B. Help seeking behavior in patients with alcohol dependence in a tertary care hospital in eastern Nepal. I Psychiatric Association of Nepal 2011;1(1): 15-18.

9. Kakunje A, Kanaradi H, Pai G, et. al. Drinking pattern in persons with alcohol dependence with and without cirrhosis: A hospital-based comparative study. Indian J Psychiatry [serial online] 2018 [cited 2021 may 1];60:189-94. Available from: https://www.indianpsychiatry.org/text.asap?2018/60/2 189/239151

10. Adhikari TB, Risal A, Kallestrup P, et al. Alcohol consumption pattern in western Nepal: findings from the COBIN baseline survey. BMC psychiatry 19, 283(2019). https://doi.org/10.1186/s12888-019-2264-7

11. Smith S, White J, Nelson C, et al. Sever alcohol induced liver disease and the alcohol dependence syndrome. Alcohol Alcohol. 2006 May-Jun;41(3):2747. doi: 10.1093/alcalc/agl014. Epub 2006 Mar 7. PMID: 16522743.

12. Rathod SD, Luitel NP, Jordans MJD. Prevalence and correlates of alcohol use in central Nepal district: secondary analysis of a population-based crosssectional study. Global mental health, ncbi,nlm.nih.gov 
13. Sharma B, Devkota A, Pant SC, Psychiatric Comorbidities in Patients with Alcohol Dependence Syndrome in a Tertiary Care Centre: A Cross-Sectionla Study. Journal Lumbini Medical College.2018;6(2):5 pages. Doi: 10.22502/jlmc.v6i2.266. Epub:2018Dec 27.

14. Singh P, Karmacharya S, Khadka S, et. al. Alcohol Induced Psychotic Disorder: Prevalence and Risk Factors. Journal of Psychiatrist's Association of Nepal, 2020; $9(1): \quad 41-46$. https://doi.org/10.3126/jpan.v9i1.31335

15. Shakya DR. Alcohol use/abuse in suicide attempters: a study in psychiatric out-patient clinic of a teaching hospital of eastern Nepal. MOJ Addict Med Ther. 2018;5(1):25-29.

10.15406/mojamt.2018.05.000086

16. Shivani R, Goldsmith J, Robert M, et al. Alcoholism and Psychiatric Disorders Diagnostic Challenges. Alcohol Research and health. 2002;26(2):90-98. 